\title{
Research on the Temperature Rise Characteristics of Elevator Driving Machine in Plateau Environment
}

\author{
Dingdong Zou ${ }^{1, a}$, Xiao Lv ${ }^{1, b, *}$, Ciren Luobu ${ }^{2, ~ c}$, Ting Yang ${ }^{2, d}$, Zaxi Nima ${ }^{2, e}$ \\ and Lixin Sun ${ }^{1, f}$
}

${ }^{1}$ Chongqing Special Equipment Inspection and Research Institute, Chongqing 401121, China

${ }^{2}$ Tibet Special Equipment Inspection Institute, Lhasa 850000, China

acq_zdd@163.com, blvxiao87@126.com

The corresponding author: Xiao Lv

Keywords: Plateau, Elevator, Driving Machine, Temperature Rise, Inspection.

\begin{abstract}
In view of the running safety in elevator under plateau environment, the temperature rise of elevator driving machine is inspected as the breakthrough point for research. Based on Simplified formula theory, the heating condition of elevator in plateau environment is discussed. The correctness of theoretical analysis is verified by the field inspection in Lhasa and Chongqing. The inspection results show that surface temperature rise of driving machine under the plateau environment is higher than plains area. These studies laid the foundation for further exploring the elevator safety performance in plateau environment.
\end{abstract}

\section{Introduction}

The land area, 2000 meters above sea level around the word, is 1,980 square kilometer, corresponding to two China. With the deepening of China's western development strategy, the western economic developed rapidly, and the elevator quantity of highland was also increasing rapidly in recent years. At present, the elevator in Tibet Autonomous Region is over 7,000, and the annual rate of growth is more than 20 per cent. In Qinghai province, the amount of elevator is over one million. High altitude area has the characteristics of thin air, low pressure, low oxygen content, large temperature difference between day and night, strong ultraviolet radiation, dry climate, complex terrain and so on. Therefore, understanding the influence of plateau environment on elevator safety has great practical significance.

\section{Background}

In China, about $60 \%$ of the total land area is more than 1,000 meters above sea level. Chinese standards about elevator lay out the using conditions of elevator are below 1,000 meters, but there aren't obvious standards and regulations to support, nor reported in the literature, that means, the adaptability of the existing elevator standards on plateau has not yet been determined that, whether we need to take extra technical measures to install and use the elevators at high altitudes above 1,000 meters. Further, it's unclear that whether the mechanical, electrical and material properties of the elevator will be changed in the plateau, if changed, is it necessary to make the scientific correction, especially in the type test? Like these questions need to be solved. Based on the above problems, the temperature rise test has been done in traction elevator motor in Lhasa, it lays a certain foundation for exploring the operation characteristics of plateau environment.

\section{Theoretical Analysis}

The motor of elevator is an important mechanism of energy converting between mechanical and electrical. However, the loss will be generated during the working process of motor. These losses for the most part eventually become heat which can cause in all parts of the motor temperature rise. As we 
all know, the losses of motor mainly include iron core losses, winding losses and mechanical losses, etc.

Iron core losses including basic iron core loss and the additional iron core loss. Due to different causes, basic iron loss can be divided into magnetic hysteresis losses and eddy current losses. Because both occurred in the core, it is not necessary to calculate respectively. Winding loss is composed of basic copper loss and the additional copper loss. Basic copper loss is caused by the current in the winding wire. Additional copper loss is made up of slot leakage magnetic field and harmonic magnetic field which produced by the wear and tear. Mechanical losses mainly include the ventilation loss, bearing friction loss and brush friction loss.

At present, the calculation method of temperature rise mainly include the simplified formula method, the equivalent heat path method, temperature field and the coupling field method. The simplified formula method is commonly used methods for motor factory, according to the Newton cooling formula as follows:

$$
\Delta T=\frac{Q}{\alpha}
$$

Where, $Q$ is Loss of load heat flux density, $\alpha$ is coefficient of heat release, $\Delta T$ is temperature rise. Due to the effect of pressure and temperature in plateau environment, air density is reduced. The coefficient of heat release $\alpha$ for thermal radiation products is reduced, so the rise temperature increase monotonously.

\section{Experimental Result}

In order to study the characteristic of elevator in plateau further, the inspection activity is taken place in Lhasa. There are two elevators as test object which manufactured by Shanghai mitsubishi elevator co., LTD. The elevators is used in Lhasa YuanDingYuan biotope (altitude $3674 \mathrm{~m}$ ), which model is HOPE-2. The model of driving machines is EM2430. The temperature is 25 degrees Celsius in machine room, humidity is $45.5 \%$, and the balance coefficient of elevator is 0.48 .

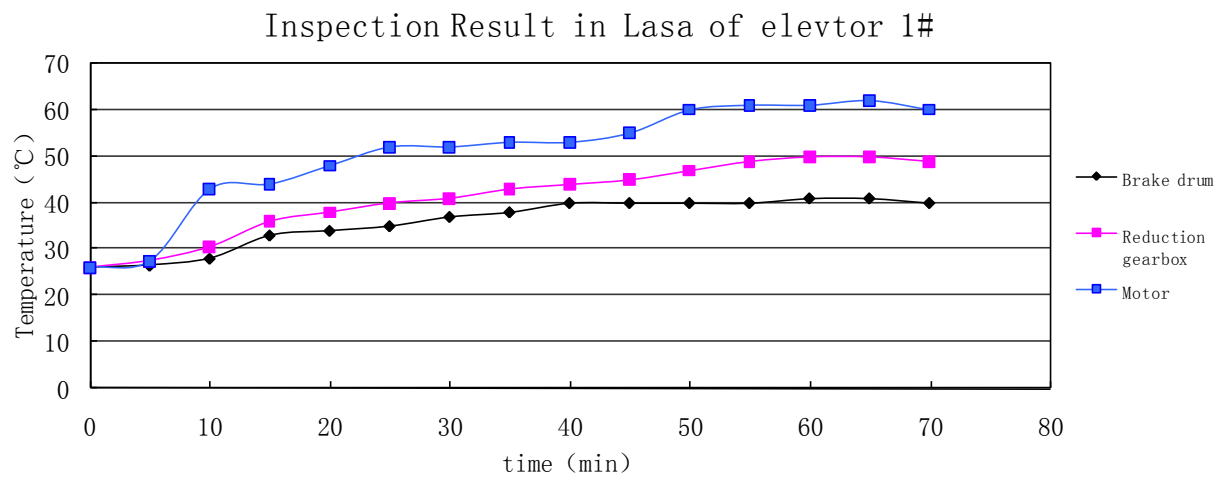

(a) Elevator 1\#

Inspection Result in Lasa of elevtor $2 \#$

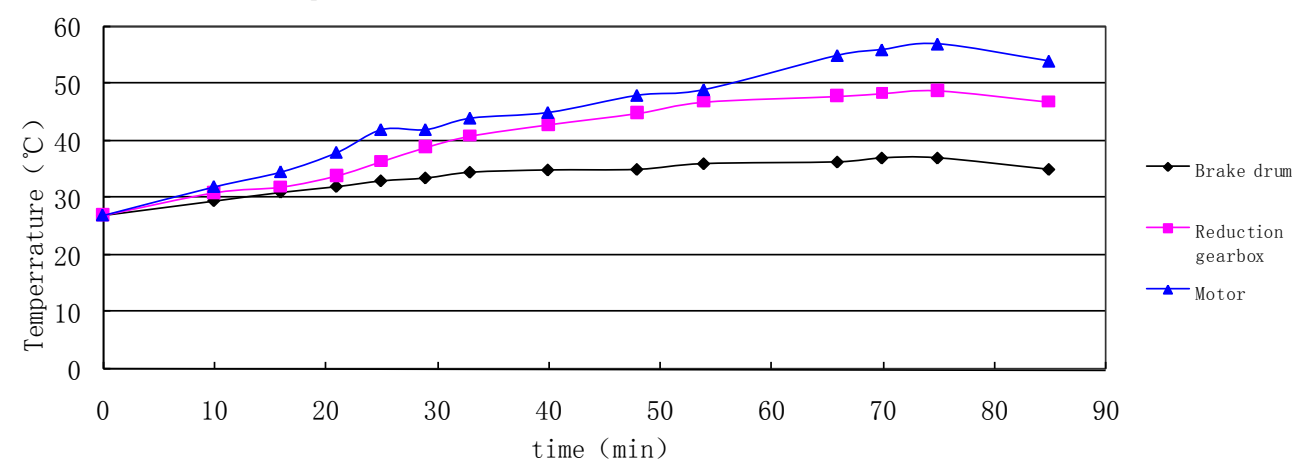

(b) Elevator 2\#

Fig.1 Inspection Result in Lhasa 
When the cyclic duration is $60 \%$, elevator is running in full load for inspection under the normal operating voltage. Surface temperature is recorded with infrared thermal imager FLUKE Ti10 per five minutes. Surface temperature mainly include the brake drum temperature, reduction gearbox temperature and motor surface temperature. The inspection is finished until the thermal steady state. As shown in Fig.1, the experimental results in Lhasa are obtained.

Fig. 1 shows that the rise temperature in motor surface temperature is $35 \mathrm{~K}$ of elevator $1 \#$, the rise temperature in reduction gearbox temperature is $24 \mathrm{~K}$ of elevator $1 \#$, and the rise temperature in brake drum temperature is $15 \mathrm{~K}$ of elevator $1 \#$. Besides, the rise temperature in motor surface temperature is $30 \mathrm{~K}$ of elevator $2 \#$, the rise temperature in reduction gearbox temperature is $22 \mathrm{~K}$ of elevator $2 \#$, the rise temperature in brake drum temperature is $10 \mathrm{~K}$ of elevator $2 \#$.

In the same way, the inspection activity is taken place in Chongqing (altitude $298 \mathrm{~m}$ ). As shown in Fig.1, the experimental results in Chongqing are obtained. Fig. 2 shows that the rise temperature in motor surface temperature is $27 \mathrm{~K}$, the rise temperature in reduction gearbox temperature is $16 \mathrm{~K}$, the rise temperature in brake drum temperature is $8 \mathrm{~K}$.

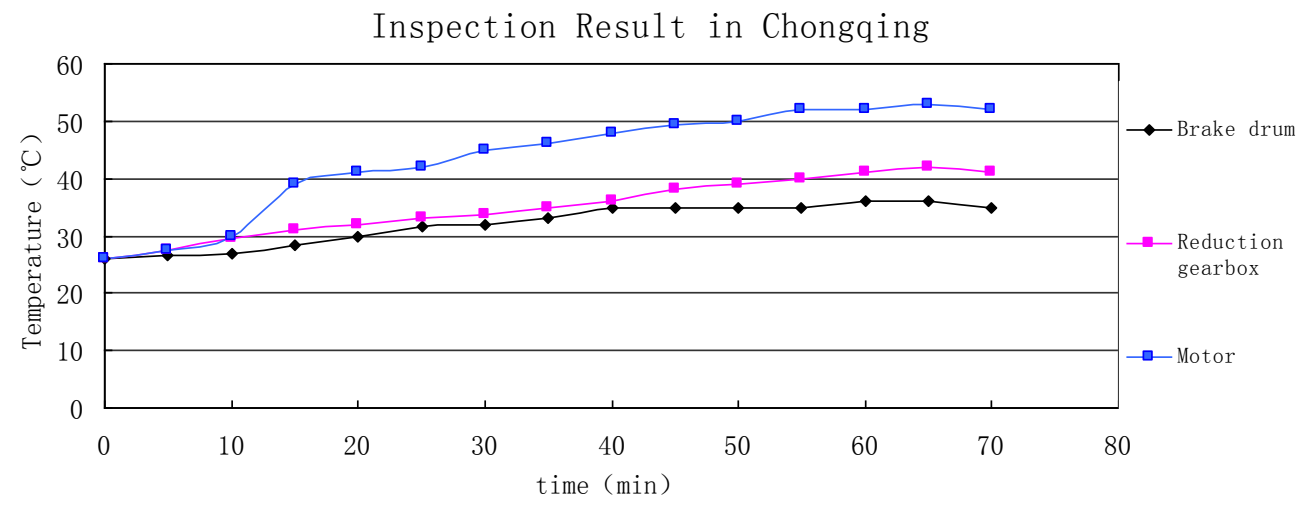

Fig.2 Inspection Result in Chongqing

It can be seen from experiment results that the before analyze is accuracy. The maximum gap of rise temperature is $8 \mathrm{~K}$ while the minimum gap of rise temperature is $2 \mathrm{~K}$ for different location of elevator.

According to the regulations of the relevant standards, the value for increase of temperature rise in electrical products is during 0.2 to $0.4 \mathrm{k}$ when altitude rises 100 meters. The calculation results agreed with the experiment results. The results show that the surface temperature rise of driving machine under the plateau environment is higher than plains area, however, considering the environmental temperature in plateau is lower than in plains, to some extent compensate for the increasing the temperature rise of the driving machine in plateau. Therefore, the motor of elevator does not need additional design in plateau.

\section{Summary}

In view of the running safety in elevator under plateau environment, the temperature rise of elevator driving machine is inspected as the breakthrough point for research. Based on Simplified formula theory, the heating condition of elevator in plateau environment is discussed. The correctness of theoretical analysis is verified by the field inspection in Lhasa and Chongqing. The results show that the surface temperature rise of driving machine under the plateau environment is higher than plains area, however, considering the environmental temperature in plateau is lower than in plains, to some extent compensate for the increasing the temperature rise of the driving machine in plateau. Therefore, the motor of elevator does not need additional design in plateau. Then, the research based on the electrical characteristics of elevator (voltage endurance, insulating properties, the clearance to earth, etc.) Will be studied further. 


\section{Acknowledgements}

This work is supported by science and technology planning project of General Administration of Quality Supervision, Inspection and Quarantine of the People's Republic of China (No.2015QK183 \&2015QK189) and Chongqing bureau of quality and technology supervision (No.CQZJKY2015007).

\section{References}

[1]Liu Huikai,Yang Li, Sun Fengrui. Research on the surface temperature rise of asynchronous motor [J]. Laser and infrared, 2006, 36(2) 118-121.

[2]Xu Jinhai, Zhang Shikuo, Zhou Tong. Design and analysis of energy saving and environmental protection type mixing station. Construction Mechanization, 6(2014)97-98.

[3] International Organization for Standardization, Energy performance of lifts,escalators and moving walks-Part 1 Energy and conformance, TC178/WG10, 2010.11.1.

[4]W. Lajnef, J.M.V.O., Characterization methods and modelling of ultracapacitors for use as peak power sources. Journal of Power Sources, 2007. 553-560.

[5]He, J.P., et al., Design and Implementation of an Energy Feedback Digital Device Used in Elevator. IEEE TRANSACTIONS ON INDUSTRIALELECTRONICS, 2011, 58(10). 4636 -4642 . 